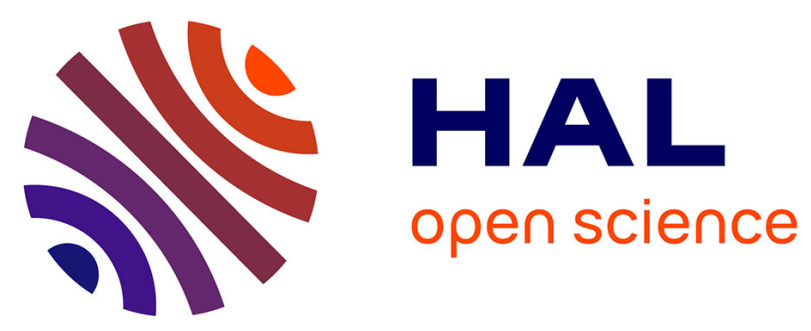

\title{
Acquisition and analysis of road incidents based on vehicle dynamics
}

Claire Naude, Thierry Serre, Maxime Dubois-Lounis, Jean-Yves Fournier, Daniel Lechner, Michèle Guilbot, Vincent Ledoux

\section{To cite this version:}

Claire Naude, Thierry Serre, Maxime Dubois-Lounis, Jean-Yves Fournier, Daniel Lechner, et al.. Acquisition and analysis of road incidents based on vehicle dynamics. Accident Analysis \& Prevention, 2017, 10.1016/j.aap.2017.02.021 . hal-01540863

\section{HAL Id: hal-01540863 \\ https://hal.science/hal-01540863}

Submitted on 16 Jun 2017

HAL is a multi-disciplinary open access archive for the deposit and dissemination of scientific research documents, whether they are published or not. The documents may come from teaching and research institutions in France or abroad, or from public or private research centers.
L'archive ouverte pluridisciplinaire HAL, est destinée au dépôt et à la diffusion de documents scientifiques de niveau recherche, publiés ou non, émanant des établissements d'enseignement et de recherche français ou étrangers, des laboratoires publics ou privés. 


\section{Acquisition and analysis of road incidents based on vehicle dynamics}

Claire Naude ${ }^{\mathrm{a} *}$

claire.naude@ifsttar.fr

Thierry Serrea

thierry.serre@ifsttar.fr

Maxime Dubois-Lounisa

maxime.dubois-lounis@ifsttar.fr

Jean-Yves Fournier ${ }^{a}$

jean-yves.fournier@ifsttar.fr

Daniel Lechner ${ }^{\mathrm{a}}$

daniel.lechner@ifsttar.fr

Michèle Guilbot ${ }^{\mathrm{a}}$

michele.guilbot@ifsttar.fr

Vincent Ledoux ${ }^{\mathrm{b}}$

vincent.ledoux@cerema.fr

${ }^{a}$ IFSTTAR (French Institute of Science and Technology for Transport, Development and Network), Laboratory of Accident Mechanism Analysis, 304 Chemin de la Croix Blanche, 13300 Salon de Provence, France

${ }^{b}$ Cerema (Centre For Studies and Expertise on Risks, Environment, Mobility, and Urban and Country Planning), Technical Division for Territorial Development and Urban Planning 2 rue Antoine Charial, 69426 Lyon, France

* Corresponding author.

\section{Accident Analysis \& Prevention}

Available online 9 March 2017

https://doi.org/10.1016/j.aap.2017.02.021 


\begin{abstract}
Because motor vehicle crashes have decreased during the last decade in many countries in the world and are more diffuse, local authorities have difficulties to define road safety policies. An experiment with 51 cars of public fleets equipped with a specific Event Data Recorder was carried out in France during one year. The purposes of this research were to evaluate if incident data (critical driving situations) help to understand crashes, and to explore a new way for road infrastructure safety diagnosis. The analysis of 339 genuine incidents and 1237 simple events recorded illustrates the potentiality of such an experiment and provides: some insights about conditions in which incidents occur, a general overview of their distribution according to different road layouts, as well as information on the different levels of accelerations reached. It can be noticed that there is an overrepresentation of incidents in right curves compared to left curves. The simple events involving mostly the infrastructure could be used to detect road defects. Genuine incidents where the vehicle is subjected to important dynamic demands, related to potentially unsafe driving situations, can be used to improve knowledge of the motor vehicle crashes thanks to incident mechanisms analysis.
\end{abstract}

Keywords: Incident; Recorder; Crash; Infrastructure; Vehicle dynamics; Road safety

\title{
1 Introduction
}

Motor vehicle crash data are a useful source of information that help to define road safety policies and especially to identify black spots on road networks where the road infrastructure should be improved. As an example, the study of De Pauw et al. (2014) evaluated the safety effects of an extensive black spot program implemented in Flanders-Belgium. 134 black spot locations were identified and modified. Changes concerned a new layout of priority or the installation of traffic signals. Results showed a high decrease in injury crashes. The treatment of black spots is proved to be an effective traffic safety measure. Sørensen and Elvik (2007) drew a state-of-the-art of the black spot management and made recommendations to identify hazardous sites with empirical Bayes method on the basis of crashes located, traffic and road data.

However the number of motor vehicle crashes has decreased during the last decade in many countries in the world, as it is shown in the IRTAD Report (2014) especially for road fatalities. It induced a lack of reliable data, with more diffused crashes, and local authorities have difficulties to set priorities in their intervention policy on their road network.

Beyond the fatal and injury crashes, there are damage-only crashes, generally without any statement of police officers and statistic follow-up. Then there is the huge field of incidents, sometimes called nearcrashes and corresponding to critical driving situations, considered as risky, because the vehicle reaches high dynamics demands in longitudinal, lateral or combined directions. Its behaviour is not controlled or at the limit of control by the driver, and ends with no impact or material damage. Under slightly different circumstances they could have resulted in injury or material damage.

The statistic model of the Heinrich's risk pyramid (1931) gives an estimation of the relationship between industrial accidents with major injury, minor injury and without injury but with material damages. The base of the pyramid is constituted by incidents. The ratio indicates clearly how senseless it is to direct the efforts only at the relatively few crashes resulting in serious injury or fatality, when there are so many significant opportunities with incidents that provide a much larger basis to study and maybe prevent crashes.

Previous researches gave some results about the link between road crashes and incidents. Naturalistic Driving Studies (NDS) were conducted in many countries all over the world (Dingus et al., 2006) using EDR 
(Event Data Recorder) and video camera to collect large-scale data, among which were identified numerous critical situations, including crashes, near-crashes and incidents. Wu et al. (2014) identified significantly positive correlations between crashes, near crashes, and crash-relevant incidents, suggesting that drivers involved in more safety-related events are more likely to be involved in a crash. A positive correlation between individual risk of the driver and his preceding crashes had also been established (Guo et al., 2010).

These NDS studies have shown that the link between crashes and incidents could exist, even though it is difficult to generalize. As explained by Valero-Mora et al. (2013), the interest of NDS is real, but the huge amount of data requires a lot of time and resources to be transferred and analysed. They presented the other inconveniences of NDS: the common use of conspicuous and costly equipment, and the fact that participants do not use their own car, which may induce a riskier behaviour.

A methodology to detect periods of interest by a less heavy and more automated way is to use EDRs (Event Data Recorders), which gives access to vehicle dynamics and detect abnormal situations. This study aims at evaluating how it is possible to detect incidents only with the vehicle dynamics. The focus on the incidents triggered in real time also constitutes a new original way to improve the understanding of crashes by completing crash data with incident data.

\section{$2 \quad$ Material and methods}

\subsection{EMMA device and incident criteria}

This study is based on the Event Data Recorder (EDR) called EMMA (Embedded data logger for crash mechanisms) which was designed in 2007 (Lechner and Naude, 2011). The aim of this device is to detect some critical driving situations, called incidents, in which vehicle is faced to high dynamics demands in longitudinal, lateral or combined directions.

The main ideas followed for the design of this EDR were to improve performances compared to existing products. The objective was to facilitate the work for its implementation in vehicle fleets and for data collection (with automatic transfer by secured GSM connection). But also to have a good compromise between quality of signals and low cost sensors. Moreover it allows respecting the law about the protection of privacy with regards to the processing of personal data. Indeed, in order to obtain an authorization from the CNIL (French data protection authority), the objective is to limit the data acquisition periods to driving situations of interest from a research point of view: incidents and crashes.

EMMA continuously acquires:

- $\quad$ Analog data from sensors directly integrated into the EDR (3 axis 2G-accelerometers and gyrometers for naturalistic driving, and 2 axis 35G-accelerometers for crash),

- $\quad$ Data provided by a GPS (trajectory and speed),

- $\quad$ Data available on vehicle on-board diagnosis system (CAN bus, information depending on the car model).

The data are analysed using real-time processing performed by the embedded software, to detect potential situations of interest. The processing is based on the following principles: when acceleration and jerk signals exceed simultaneously some thresholds, an event is triggered. The data are recorded during the $30 \mathrm{~s}$ before and the $15 \mathrm{~s}$ after the trigger and stored in the device. Then the complete report containing the whole data 
set at $100 \mathrm{~Hz}$ frequency is automatically sent to a server using GSM network. Finally the event is examined and validated by an operator and if it is considered of interest, stored in the global database.

In addition the GPS data of all the itineraries are recorded, but stored with 1 position per minute only and in a separate file, in order to have the traffic of the equipped vehicles but not their precise travels. Data about kilometres travelled by vehicles allow calculating the risk exposition.

Because this study is based on the detection of incidents, one of the crucial parts of the work was to define the criteria which can allow identifying an incident. The objective of the current method is to be able to detect safety critical behaviour using vehicle dynamics behaviour.

Many previous works were conducted to analyse driver behaviour like Raksincharoensak et al. (2008), Ikenishi et al. $(2010)$ or Lechner and Perrin $(1993,1996)$. This last study has shown that the average drivers exceed $3 \mathrm{~m} / \mathrm{s} 2$ only $2 \%$ of their driving time. Moreover only a few drivers exceed very rarely $5 \mathrm{~m} / \mathrm{s} 2$, mostly in lateral, representing hardly $0.1 \%$ of their driving time. These works provided objective elements of dynamic demands encountered in an incident.

Chosen criteria take into account longitudinal, lateral and coupled demands. The acquisitions are automatically triggered from a combination of speed, accelerations and jerk signals (i.e. the rate of change of acceleration). Indeed, it was proven by Bagdadi and Várhelyi (2011) and Bagdadi (2013) that jerk analyses make it possible to identify safety critical driving behaviour. Finally the chosen levels are quite similar to those proposed in Nagai et al. (2006) modulated by the influence of speed.

The retained thresholds are the following:

- $\quad$ Speed $<80 \mathrm{~km} / \mathrm{h}$, and Acceleration norm $>6 \mathrm{~m} / \mathrm{s} 2$ and Jerk $>2 \mathrm{~g} / \mathrm{s}$,

- $\quad$ Speed $>80 \mathrm{~km} / \mathrm{h}$ and Acceleration norm $>5 \mathrm{~m} / \mathrm{s} 2$ and Jerk $>2 \mathrm{~g} / \mathrm{s}$,

- $\quad$ Speed $>100 \mathrm{~km} / \mathrm{h}$ and Acceleration norm $>4 \mathrm{~m} / \mathrm{s} 2$ and Jerk $>2 \mathrm{~g} / \mathrm{s}$.

As soon as the vehicle dynamic parameters exceed one of these three thresholds combinations, it is considered that something "abnormal" happened on the vehicle and consequently an "event" is stored.

\subsection{Sample of vehicles}

51 EMMA were built and implemented in light vehicles of five different public fleets located in the north of France (Normandie-Centre area), in the centre (Auvergne area) and in the south (Salon de Provence).

All these vehicles were company vehicle, dedicated or not to one person. The dedicated ones could be only driven by one specific driver when the other could be driven by all the authorized employees of the involved organisms.

The fleets were composed of various car models from French car makers "Renault", "PSA" (Clio, Megane, Laguna, Twingo, 307, 308...).

\subsection{Data processing}

The data collection of numerous events brought out the necessity to distinguish two types of events: simple events which are non-risky situations and genuine incidents generated by the driver, which are critical driving situations. The process of classification is semi-automatic and takes into account the amplitude and 
the duration of the accelerations signals, as shown on Fig. 1. In the EMMA device, a first classification is operated in real time with the help of different filtering of the signal ( 3 points average for genuine incidents). Then the examination of measurements by an operator allows refining the classification.

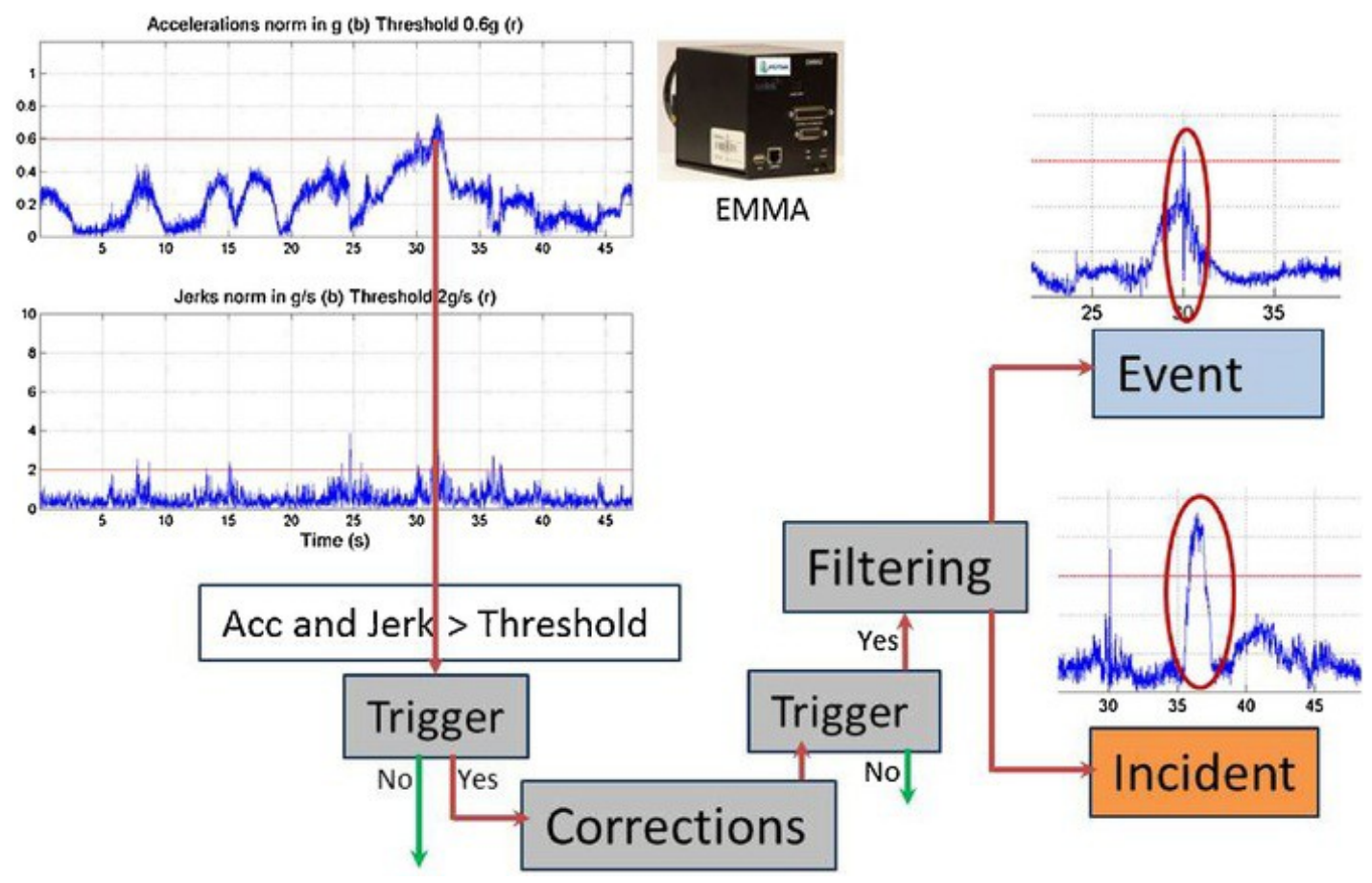

Fig. 1 Principle of classification for simple events and genuine incidents.

Simple events are mostly characterized by very short durations of acceleration peaks. They are generally caused by a local defect of the pavement or a layout of the road, like a level crossing, a bridge junction, rumble strips, a pavement deformation, a cobblestone area... They are not considered as relevant for the road safety concerns, but they could be useful for road managers to detect road pavement defects and therefore plan reparations and/or alert drivers (See Serre et al., 2013).

Genuine incident criteria are higher durations of accelerations, resulting from driver actions beyond a $3 \mathrm{~Hz}$ frequency. It is considered of interest as a risky driving situation.

\section{$2.4 \quad$ Juridical context}

All the legal conditions to implement EDR in French public fleets of vehicles were respected in accordance to the prescriptions of the CNIL (French data protection authority). These conditions integrate European regulations and respect of Human Rights.

The data collection was therefore limited to driving situations of interest from a research point of view. Moreover, to ensure personal data protection, drivers were informed about the experiment objectives and had to be volunteers: their consent was free, enlightened and specific.

EDR were thus inactivated by default, and volunteer drivers had to opt-in by pushing a button to start the recording for each itinerary. Moreover their hierarchical managers had no access to their data. 


\subsection{Global results}

About 500 non-professional drivers were asked to participate. Among them 221 were volunteers to take part to the experiment, agreeing to drive an equipped vehicle during their professional travels.

The whole database for one year represents 3052 itineraries and $106645 \mathrm{~km}$, distributed on the 51 vehicles fitted with EMMA. It enabled to collect 339 genuine incidents and 1237 simple events on the French road network, as illustrated in Fig. 2. It can be noticed that some accumulations of incidents were observed when they occurred at different time at the same place. The 3052 itineraries cover not only roads around the geographical parking areas of the equipped vehicles but also roads far beyond them.

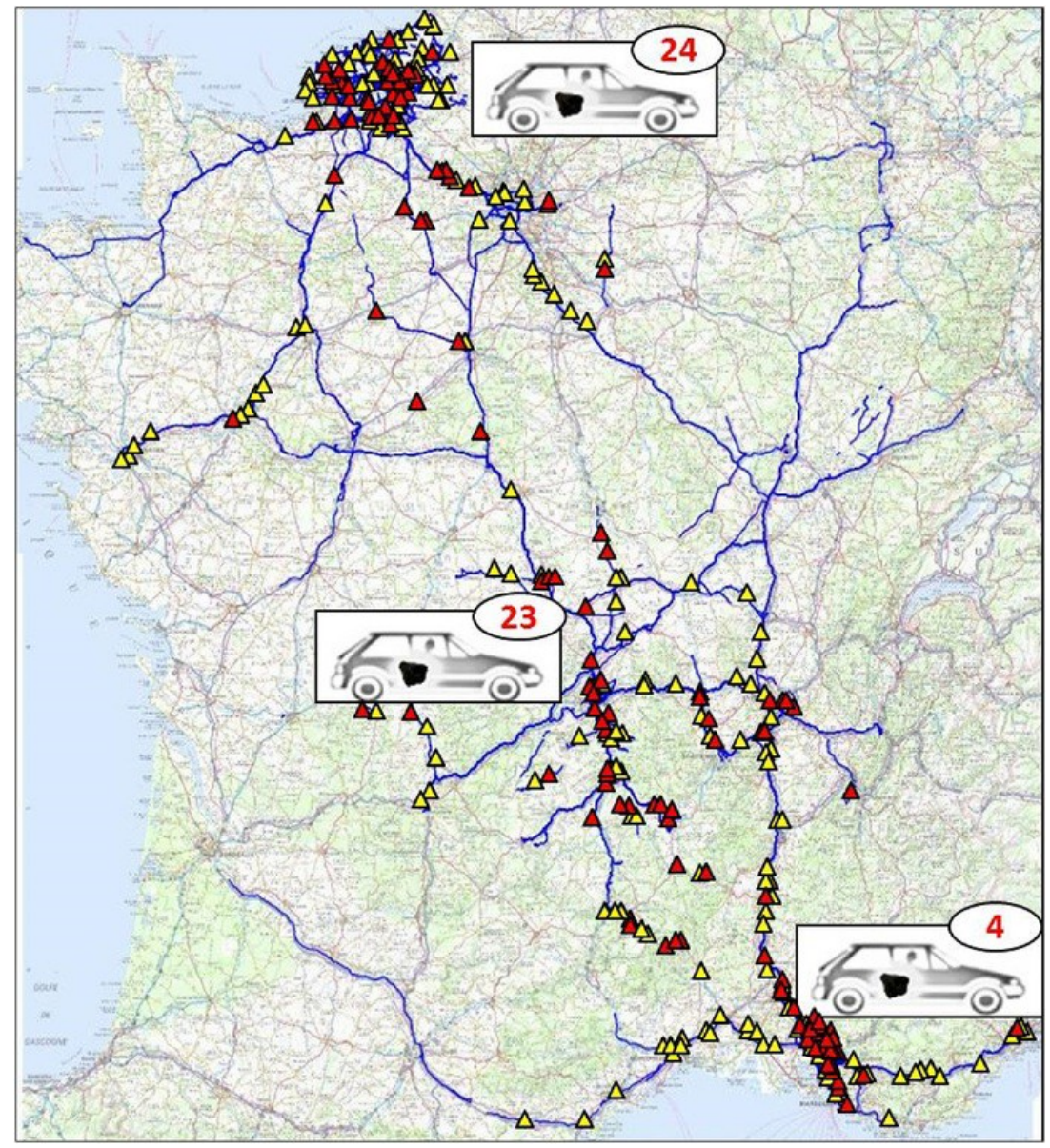

Fig. 2 Geographical repartition of the 339 genuine incidents (red/dark triangles), the 1237 simple events (yellow/pale triangles) and the 3052 itineraries in France (blue/dark roads). (For interpretation of the references to color in this figure legend, the reader is referred to the web version of this article.)

The study of the sites where the simple events occurred could help road managers to detect road defects. Since these events are not due to the driver behaviour, they are not taken into account in this paper. The analysis of mileage revealed one incident every $350 \mathrm{~km}$ or every $5 \mathrm{~h}$ of driving. Considering all kilometres travelled by all cars in circulation in France, compared to their number of motor vehicle crashes with injuries inventoried by law forces (O.N.I.S.R., 2011), results give in first intention a ratio of one crash with injuries per 20000 dynamic incidents (Fournier and Naude, 2014). 


\subsection{Examples of incidents}

\subsubsection{Longitudinal incident: braking approaching an intersection}

The left part of Fig. 3 illustrates a braking configuration which took place on a straight road when the driver approached an intersection. The trajectory during the recording period begins at the point " $\mathrm{B}$ " and ends at the point " $\mathrm{E}$ ", and the trigger is just before the intersection (point " $\mathrm{T}$ "). The vehicle speed was stabilized using the cruise control at about $90 \mathrm{~km} / \mathrm{h}$ when the driver started to brake. During the braking, ABS (Antilock Brake System) and BAS (Brake Assistance System) were triggered. The braking distance was approximately $30 \mathrm{~m}$ and the average deceleration was about $-7.6 \mathrm{~m} / \mathrm{s} 2$, with a maximal peak at $-11 \mathrm{~m} / \mathrm{s} 2$. A light offset towards left was observed with a bit of lateral acceleration.

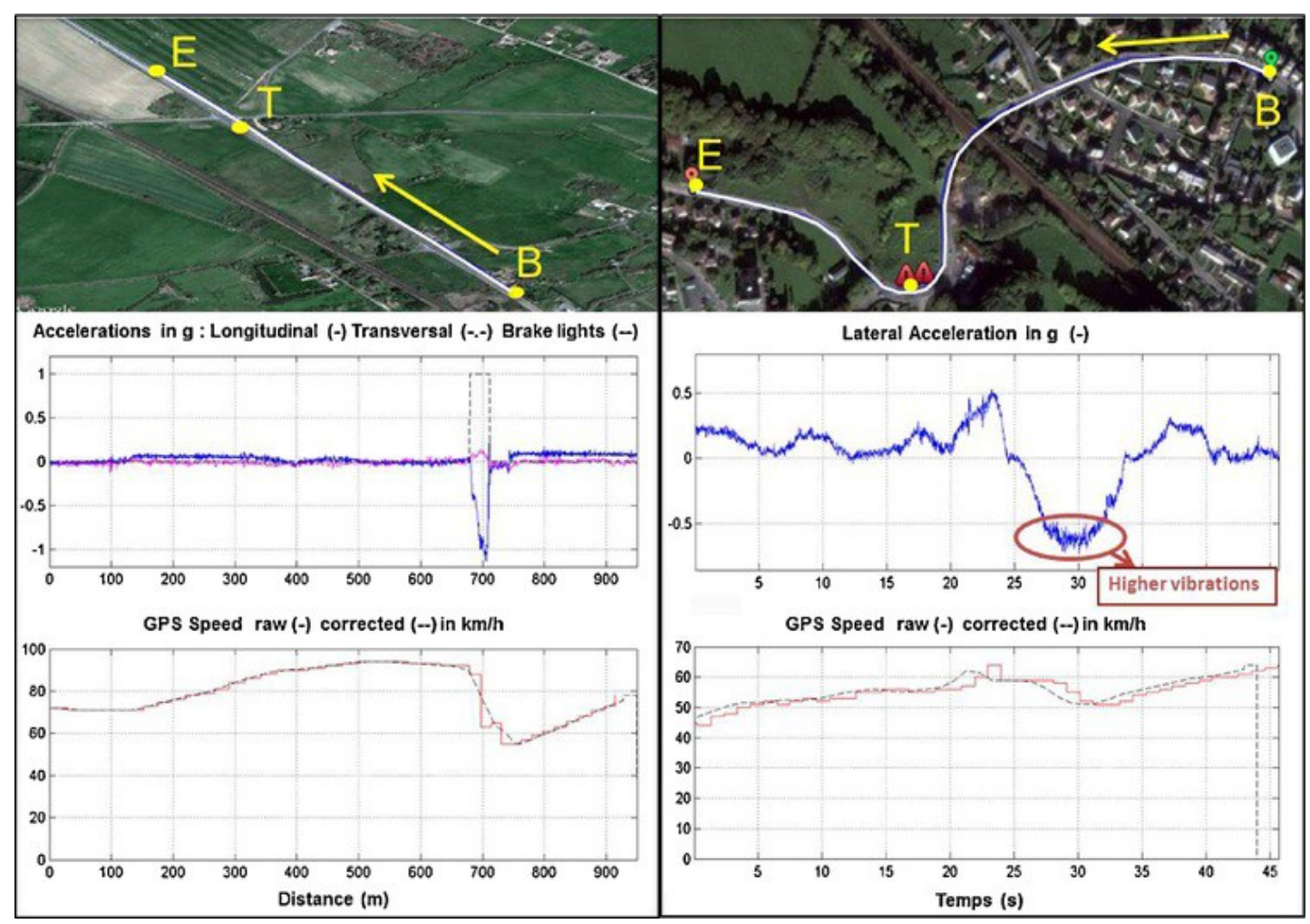

Fig. 3 Longitudinal Incident with emergency braking (Left) and lateral Incident in a tight curve (Right): trajectory on the site, accelerations, speed.

A likely hypothesis for the causes of this incident is: the arrival of a vehicle on the transversal road that could have not stopped may have frightened the driver. He accelerated again when the antagonist vehicle finally stopped at the intersection.

This type of incident is of great interest especially because it is linked with crash/hazardous situations already known and described in the scientific literature about prototypical crash scenarios (Blancher et al., 1998). According to this research, one of the prototypical scenarios can be described like that: nearing an intersection, a non-priority driver has to ease his way into the principal road but he does not detect a road user arriving on this priority road. Then the priority driver realizes an emergency braking. The detailed analysis of this incident, using especially dynamic parameters, brings knowledge on the mechanisms of this type of crash. 


\subsubsection{Lateral incident: tight curve}

Lateral incidents occur when the vehicle reaches high level of lateral acceleration. It can correspond to a vehicle going fast on a curve or a roundabout, or when the driver operates a sudden change of direction or a specific manoeuvre like an avoidance manoeuvre, with a quick variation of the steering wheel angle.

The following example concerns a vehicle negotiating a tight curve in an interurban area (Right part of Fig. 3). As shown on the photograph, two distinct incidents occur at this location at different times but only one of them is presented hereafter. The speed of the car was about $60 \mathrm{~km} / \mathrm{h}$ when approaching the curve and it decreased towards $52 \mathrm{~km} / \mathrm{h}$ along the turning phase; the lateral acceleration reached $7 \mathrm{~m} / \mathrm{s} 2$. It can also be observed higher vibrations in the more demanding part of the curve. The $36 \mathrm{~m}$ curve radius is very small for an isolated curve, and there are no specific speed limit signs on the road. In this case, even if the driver has to keep control on his vehicle, it can be considered that the infrastructure plays an important part in the causation of the incident. This curve is a risky zone because of its geometric design which requires a high variability of operating speeds. It can affect the likelihood of crashes.

Even more, if the weather had been snowy and the road wet or icy, it can be estimated that with these levels of accelerations and the low adherence conditions the incident should have degenerated into a loss of control.

\subsection{A material crash: impact against a pole}

Crashes were considered when the level of accelerations was higher than $15 \mathrm{~m} / \mathrm{s} 2$. Only one material crash was recorded during the data collection. It corresponds to a little impact against a pole at a very low speed during a reverse manoeuver (under $5 \mathrm{~km} / \mathrm{h}$ ). The longitudinal acceleration (from the crash 35Gaccelerometer) almost reached $28.5 \mathrm{~m} / \mathrm{s} 2$.

\subsection{Dynamic demands of genuine incidents}

In order to differentiate vehicle dynamic behaviours and to classify the incidents, the criteria considered were derived from the friction circle. They were introduced in Serre et al. (2014). The incidents can be classified beyond the threshold of $6 \mathrm{~m} / \mathrm{s} 2$ (or $5 \mathrm{~m} / \mathrm{s} 2$ or $4 \mathrm{~m} / \mathrm{s} 2$ ) for the norm of accelerations. An incident is considered as mainly longitudinal (respectively lateral) if the absolute value of the acceleration on the $x$-axis (resp. y-axis) exceeds the threshold. Fig. 4 shows the distribution of the 339 incidents according to the main dynamical demands on the vehicle in longitudinal, lateral or combined directions. Incidents with a high/emergency braking (resp. with a high acceleration), corresponding to a negative (resp. positive) longitudinal acceleration, are counted in the lower (resp. upper) part of the graph. Incidents with a positive (resp. negative) lateral acceleration corresponding to a left (resp. right) turn are counted in the right (resp. left) part of the graph. If the threshold is exceeded by the combination of both longitudinal and lateral accelerations, the incident is considered as a combined demand (dark parts of the graph). The circles with 4, 5 and $6 \mathrm{~m} / \mathrm{s} 2$ radius represent the level of acceleration beyond which an incident is triggered if speed exceeds 100 and 80 , or is lower than $80 \mathrm{~km} / \mathrm{h}$ respectively. 


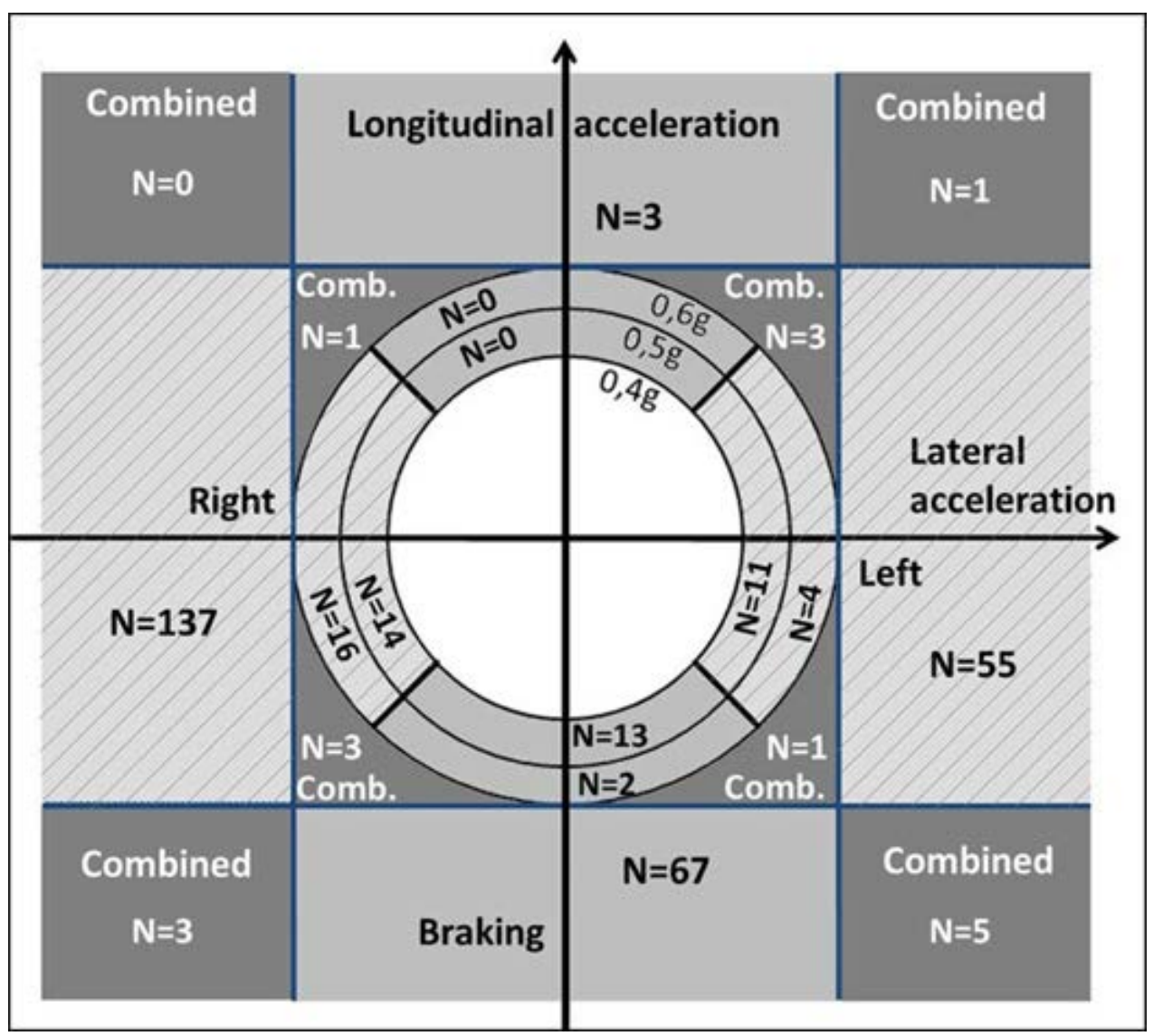

Fig. 4 Distribution of incidents according to the main dynamical demands on the vehicle.

It can be noticed that $70 \%$ of the incidents concern lateral accelerations (237 cases), $25 \%$ longitudinal (85) and $5 \%$ a combination of both (17). Among the lateral incidents, right turns represent $70 \%$ against $30 \%$ for left turns.

The triggering acceleration is between 4 and $5 \mathrm{~m} / \mathrm{s} 2$ in $11 \%$ of cases, which correspond to speeds higher than $100 \mathrm{~km} / \mathrm{h}$, and between 5 and $6 \mathrm{~m} / \mathrm{s} 2$ in $9 \%$ of cases, with speeds between 80 and $100 \mathrm{~km} / \mathrm{h}$. For longitudinal triggering, speed exceeds $100 \mathrm{~km} / \mathrm{h}$ for $16 \%$ of braking incidents. The 3 positive longitudinal accelerations beyond $6 \mathrm{~m} / \mathrm{s} 2$ correspond to one slight collision (material crash reported in paragraph 3.4), one pothole and one abrupt start with wheel spin. Combined incidents are associated to specific city planning such as roundabout, or a specific manoeuvre such as a braking in a curve.

Table 1 resumes the distribution of acceleration levels according to this type (longitudinal/lateral, positive/negative) and gives the average instantaneous speed according to the incident type. In addition to this table, 17 incidents were classified as combined and 9 of them with very high dynamic values. 
Table 1 Distribution of acceleration levels in function of the type of incidents and associated average of instantaneous speed of the vehicles.

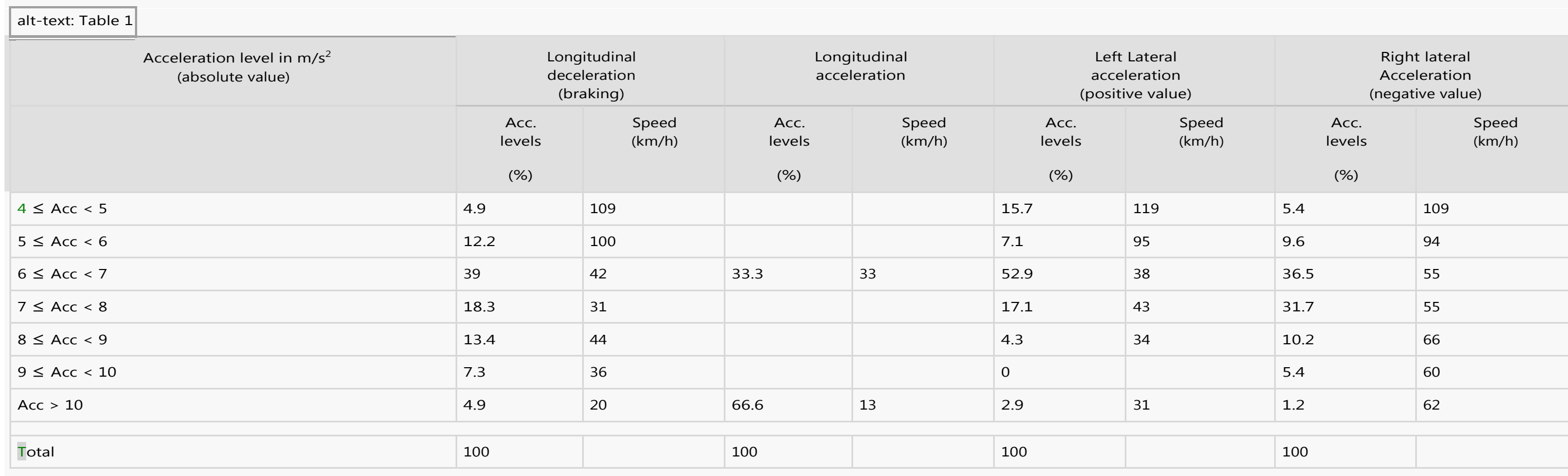

Table 1 Distribution of acceleration levels in function of the type of incidents and associated average of instantaneous speed of the vehicles. 
If $70 \%$ of lateral incidents happened in right turns, the levels of lateral acceleration, when EMMA triggered, are higher in right turns than in left turns. For instance lateral acceleration exceeds $7 \mathrm{~m} / \mathrm{s} 2$ for $48 \%$ of incidents in right turns and only for $24 \%$ of incidents in left turns.

The thresholds triggering for accelerations were defined also according to the speed. Thus it was interesting to associate the levels of accelerations with the instantaneous speed of the vehicle when its dynamic parameters reached the thresholds.

From a global point of view, it can be observed that the needed instantaneous speed to reach a lateral acceleration of $6 \mathrm{~m} / \mathrm{s} 2$ is lower in "turn left" $(\sim 0 \mathrm{~km} / \mathrm{h})$ than in "turn right" ( $\sim 60 \mathrm{~km} / \mathrm{h})$. It can be explained by the following hypotheses. In a right turn the curve radius is lower than in a left turn. In addition it is possible to increase the turning radius of left curves by cutting the path.

\subsection{Road configurations}

The breakdown according to the accelerations can be completed by the repartition of incidents in function of the driving context and type of infrastructure, in order to identify if some road configurations are more risky. First the type of driving is urban or suburban for $54 \%$ of the incidents, and rural for $46 \%$. More precisely, the major part of the incidents occurred on secondary roads (59\%), only $5.8 \%$ on main roads and $6.2 \%$ on highways. The $29 \%$ remaining occurred on urban roads or byways.

Four main types of road configurations were considered: straight road $(15.7 \%)$, curve (left $13.6 \%$ or right $41.1 \%)$, intersection (16.3\%), and roundabout (14.8\%).

The 55 incidents which took place in intersection can be distributed according to the type of junction. Three kinds of junction were considered: junction in " $T$ ", junction in " $Y$ " and junction in " $X$ ". Among these 55 incidents, 23 were generated in a " $\mathrm{X}$ " configuration (41.8\%) whereas 18 took place in a " $\mathrm{Y}$ " intersection (32.7\%) and 14 in a " $\mathrm{T}$ " junction (25.5\%). 40 incidents were due to a sudden change of direction. 28 concerned a right change (70\%) while 12 concerned a left change (30\%).

Table 2 provides additional knowledge about the distribution of the 339 incidents as a function of the road layouts involved. Pure braking actions on a straight line represent $19 \%$ of the incidents; some of them took place at an intersection. It is found again that the right/left curves represents $41 / 14 \%$ of cases, whereas turns to right/left on crossroads are the theatre of $8 / 4 \%$ of incidents respectively. The remaining (14\%) are roundabouts, with only $2 \%$ in the right curve entrances, $6 \%$ in the right curve exits and $6 \%$ in the central left turns, some of them being braking. While roundabout entrances and exits are generally transient manoeuvers, the central parts induce generally more steady state behaviours. 
Table 2 Distribution of incidents according to the type of road infrastructure layouts (curve, crossroad, roundabout...).

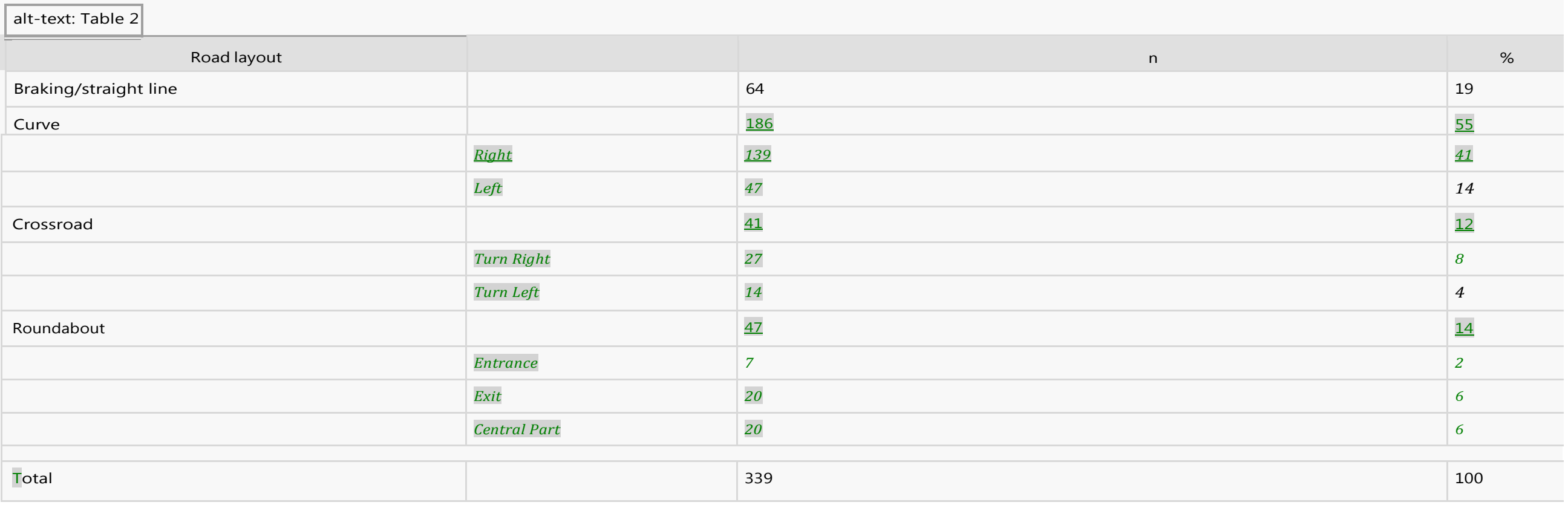

Table 2 Distribution of incidents according to the type of road infrastructure layouts (curve, crossroad, roundabout...). 
The large difference between the numbers of incidents in right/left curves (i.e. $41 / 14 \%$ ) can mainly be explained by the fact that the vehicles circulate on the right side of the road in France. This point has several consequences. First, all the motorway or main road exits are right curves, and these designs often involve high dynamic demands on the car. And on 2 way traffic roads:

The drivers can feel more confident to reach high lateral accelerations in right curves, since the opposite lane of traffic on the left may be used as a possible recovery area,

The right hand side driving offers more capabilities to increase the curve radius of left curves by cutting the path using the opposite lane of traffic,

Considering a given curve, when a vehicle turns on the right, the turning radius is slightly lower than when the vehicle turns on the left. Consequently the lateral acceleration (equal to V2/R if one neglects the side slip and the road banking) is slightly higher.

4

\section{Discussion}

This research was focused on incidents and enabled the detailed analysis of such situations, which involve high vehicle dynamical solicitations. This approach allows avoiding classical problems encountered in most of NDS studies due to the large amount of data, like the transfer, the storage and the exploitation (Valero-Mora et al., 2013; Csepinszky et al., 2012).

Sometimes the data collected were insufficient to explain the causes of incidents. The use of other tools such as cameras or feedback information by the drivers would enable to know the precise context of the incidents, and consequently to better understand the link between incidents and crashes. In some incidents, a camera or a radar in addition to the accelerations and speed would also enable to calculate the TTC (Time To Collision) in order to determine if the situation can be considered as a near-crash or not. It was for example done by Kusano et al. (2015) for drivers braking during car following scenarios. Unfortunately, it was not possible to have video data in this research because the technical conditions did not permit to respect the confidentiality aspects. These conditions are now in place for future researches. Moreover, legal constraints (CNIL) permitted to respect rights of volunteer drivers but lead to an EDR disabled by default. Volunteers had to opt-in by pushing a button for each itinerary to start the recording. These constraints induced bad consequences on the data collection: EMMA average activation rate appeared to be only about $30 \%$. More data would probably have been recorded if the EDRs were activated by default.

Furthermore, experiments with a great number of vehicles equipped would increase the probability to record some crashes. The estimation results have shown that the vehicles fleet should be very high to expect to record a crash with injury (if it can be expected!). The obtained ratio is one crash with injury per 20,000 incidents. The incidents-material crash ratio in the experiment is one material crash for 338 incidents. A previous study provides information on this point: the collection of 89000 crash-relevant-event data (Raksincharoensak, 2013) by 200 taxis in Japan, thanks to front-view cameras gives a ratio of one crash (including material) for 200 incidents. It could be interesting to get more knowledge about the material crashes in France to have the ratio extrapolated between all crashes, comprising material, and incidents.

The distribution of incidents according to the main demands on the vehicle highlighted in particular the overrepresentation of incidents in right curves compared to left ones, which can be mainly explained by the fact that the vehicles circulate on the right side of the road in France. It would be interesting to study incidents in curves in a country were the circulation is on the left side of the road. A study by Michel et al., 2005; in France showed on a sample of 84 detailed losses of control that crashes were on the contrary more 
frequent in left curves compared with right curves, except for the crashes on wet road where the repartition is balanced. The hypothesis is that the opposite lane is a good recuperation zone for the losses of control in right curves, which allows avoiding crash. In similar conditions crashes in left curves would not be avoided, due to the lack of sufficient shoulder. This is especially true for crashes involving moderate levels of acceleration. Indeed, high levels of acceleration or bad conditions of road adhesion moderate or cancel the advantage of the presence of the opposite lane. The apparent opposition between results for incidents and for crashes is explained by the fact they occur in a different time of the spatiotemporal continuum of the event:

In right curves the cars reach higher dynamic demands (See paragraphs 3.5 and 3.6), and consequently signals trigger more often, hence the high number of incidents in right curves without crash.

- $\quad$ In left curves the cars do not reach high levels of acceleration because they are quickly outside of the road, hence the number of crashes occurred. Moreover, when the drivers cut the curve, thanks to the opposite traffic lane, the lateral acceleration decreases (unless the drivers increase their speed) but this unsafe driving behaviour can lead to a collision with an oncoming vehicle.

During one year of collecting data, more than 300 genuine incidents and more than 1200 simple events were recorded on the French road network with 51 vehicles equipped, representing a high amount of data.

The results highlight the possibility of using EDR to record events with different levels of gravity: simple events or genuine incidents. Simple events involving mostly the infrastructure could be useful especially for road managers to detect and repair road defects. Genuine incidents, where the vehicle is subjected to important dynamic demands, related to potentially unsafe driving situations and including emergency manoeuvres, provide some insights about conditions in which they occur. Their analysis enables to draw a general overview of their distribution according to different road layouts, as well as information on the different levels of accelerations encountered. They can be used to improve knowledge of crash and incident mechanisms analysis. The study of left and right curves incidents (proportions, levels of acceleration and speed) brought interesting comparisons with crashes.

Afterwards, the classification system for genuine incidents should be in the future as much as possible based on automatic processing, in order to reduce the human resources dedicated to the validation and classification of the recorded events. By the way another study is ongoing to calculate automatically a severity index for each incident, taking into account the levels of accelerations, jerks and speeds, the configurations of road (curve radius...), the use of safety systems such as ABS (Anti-lock Brake System), and the levels of vibrations. The objective is to have a reliable and automatic classification of minor, moderate and major incidents, and to refine the link between incidents and crashes.

Otherwise an additional vehicle dynamics investigation is achievable from now on, with EMMA devices, since embedded calculation capabilities afforded to develop an observer of sideslip angle based on Kalman Filter. This specific development was achieved from previous work (Doumiati et al., 2012). It will enable to trigger an incident when the vehicle drifts without a high level of lateral acceleration (wet or icy road, worn tyres...). 
Further data collections on road incidents will be carried out with a smartphone version of the EMMA device, at the level of French Prefectures, with funding provided by the local authorities in charge of road infrastructure.

\section{Acknowledgements}

The authors thank the French Government (DSCR) for supporting the SVRAI project (Saving Lives through Road Incident Analysis Feedback) on road incident collection and analysis. Their gratefulness also goes to the public organizations who accepted to equip their vehicles with EDR and to the volunteer drivers. Finally, they thank the persons of IFSTTAR and Cerema who contributed to this work, especially Sébastien Chauvet, Peggy Subirats, Eric Violette, Stéphanie Bordel and Yves Bonin.

\section{References}

Bagdadi O. and Várhelyi A., Jerky driving - an indicator of accident proneness?, Accid. Anal. Prev. 43 (4), 2011, 1359-1363. Bagdadi O., Assessing safety critical braking events in naturalistic driving studies, Transp. Res. Part F 16, 2013, 117-126.

Blancher, G., Brenac, T., Fleury, D., 1998. Scénarios types d'accidents liés à une interaction entre véhicules hors agglomération. Convention INRETS/DRAST n95MT0051/1, INRETS, 47p.

Csepinszky A., Brouwer R., Kessler C., Hagleitner W., Schwertberger W., Obojski M.-A., Just M., Kuhn F., Metz B., Guidotti L., Gustafsson D., Heinig K. and Val C., Deliverable D5.4/D 4.3: Test and Vehicle Report, Summary of User Workshops, and Methodological Lessons Learned, 2012, EuroFOT, 99 http://www.eurofotip.eu/en/library/deliverables/.

De Pauw E., Daniels S., Brijs T., Hermans E. and Wets G., Safety effects of an extensive black spot treatment programme in Flanders-Belgium, Accid. Anal. Prev. 66 (8), 2014, 72-79.

Dingus T.A., Klauer S.G., Neale V.L., Petersen A., Lee S.E., Sudweeks J., Perez M.A., Hankey J., Ramsey D., Gupta S., Bucher C., Doerzaph Z.R., Jermeland J. and Knipling R., The 100-Car Naturalistic Driving Study Phas II ?-Results of the 100-Car Field Experiment, U.S. DOT HS 810 593, 2006, Department of Transportation, National Highway Traffic Safety Administration; Washington DC.

Doumiati M., Charara A., Victorino A. and Lechner D., Vehicle Dynamics Estimation Using Kalman Filtering: Experimental Validation, 2012, Wiley-ISTE.

Fournier J.-Y. and Naude C., S_VRAI pProject, Livrable 6S6_A, Pyramide des incidents: Ratio entre incidents et accidents: Convention DSCR/CERTU/IFSTTAR n7624. Septembre 20142014.

Guo F., Klauer S.G., McGill M.T. and Dingus T.A., Evaluating the Relationship Between Near-Crashes: Can Near-Crashes Serve as a Surrogate Safety Metric for Crashes? DOT HS 811 382, 2010, U.S. Department of Transportation, National Highway Traffic Safety Administration; Washington DC.

Heinrich H.W., Industrial Accident Prevention: a Scientific Approach, 1931, McGraw-Hill, (Republished several times since 1980). 
IRTAD, Road Safety Annual Report 2014, 2014, International Traffic Safety Data and Analysis Group, http://internationaltransportforum.org/Pub/pdf/14lrtadReport.pdf (526p) (Last Accessed 03 September 2015).

Ikenishi T., Nishie G., Kamada T., Nagai M. and Tanaka J., Data-Driven Hurry Driving Detection Algorithm Design and Evaluation by Using Continuous-Logging Drive Recorder. Paper 202, AVEC 2010, 2010, JSAE.

Kusano et al., 2015 D.K. Kusano, R. Chen, J. Montgomery and H.C. Gabler, Population distributions of time to collision at brake application during car following from naturalistic driving data, Accid. Anal. Prev. 54 (2015), 2015, 95, e29-104.

Lechner D. and Naude C., Road incident analysis between naturalistic driving study and accident in-depth investigation, In: Proceedings of the 1st International Symposium on Future Active Safety Technology Toward Zero-traffic-accident - FASTzero'11, Tokyo, Japan2011.

Lechner D. and Perrin C., The actual use of the dynamic performances of vehicles, Proc. J. Automobile Eng. Part D 1993, (Issue D4, IMechl. SAE Paper 18-207-D4- 249.).

Lechner D. and Perrin C., Methodology to study the dynamic behaviour of the driver-vehicle system, In: Technical Paper R19.08 - FISITA 96 Congress, Praha (Czech Republic) June 17--211996.

Michel J.-E., Brenac T., Magnin J., Naude C. and Perrin C., Les pertes de contrôle en courbe: Cinématique, typologie, caractéristiques des lieux, Analyse d'un échantillon de 84 cas. Les collections de l'INRETS. Rapport $n^{\circ} 262,2005$.

Nagai M., Michitsuji Y., Kamata M., Fujita M., Shino M. and Maeda K., Research on Incident Analysis Using Drive Recorder. Part 2: Toward Active Safety Assessment. FISITA 2006 Paper F2006V202, 2006, JSAE.

O.N.I.S.R. (Observatoire National Interministériel de Sécurité Routière), 2011. La sécurité routière en France: bilan de l'année 2010. La Documentation Française, Paris.

Raksincharoensak P., lijima T., Maeda K. and Nagai M., Individual adaptation of driver assistance system based on real-world naturalistic driving database. part 2: algorithm for detecting unusual driving behaviour based on driving database, In: Proceedings of AVEC 2008, Kobe, JSAE2008, 473-478.

Raksincharoensak P., Drive recorder database for accident/incident study and its potential for active safety development, In: FOT-NET Workshop, Tokyo, Japan. October 14, 20132013 http://www.tuat.ac.jp/? smrc/pdf/Driverecorder.pdf.

Sørensen M. and Elvik R., Black Spot Management and Safety Analysis of Road Networks, 2007, Institute of Transport Economics, Norwegian Centre for Transport Research; Oslo, (No. 119/2007).

Serre T., Naude C., Chauvet S., Fournier J.-Y., Lechner D., Guilbot M. and Ledoux V., Towards a classification of road incidents acquires from public fleets of vehicles, In: Proceeding of the Second International

Symposium on Futur Active Safety Technology Toward Zero-traffic-accident. FAST-zero'13, Nagoya, Japan2013.

Serre T., Naude C., Chauvet S., Fournier J.-Y., Lechner D. and Ledoux V., Causes of Road Incidents, 2014, Proceedings of the Transport Research Arena Paris; France. 
Valero-Mora P.M., Tontsch A., Welsh R., Morris A., Reed S. and Touliou K., Katerina, Margaritis, D., 2013: Is naturalistic driving research possible with highly instrumented cars? Lessons learnt in three research centre, Accid. Anal. Prev. 58, 2013, 187-194.

Wu K.-F., Aguero-Valverde J. and P.Jovanis P., Using naturalistic driving data to explore the association between traffic safety-related events and crash risk at driver level, Accid. Anal. Prev. 72 (2014), 2014, 210218.

\section{Highlights}

- $\quad 51$ French company vehicles have been equipped with EDR.

- More than $100000 \mathrm{~km}$ and 300 incidents have been recorded.

- $\quad$ Around $70 \%$ incidents are in lateral, $25 \%$ in longitudinal.

- The incidents collection improves the road safety diagnosis.

- We progress towards understanding incident and accident mechanisms. 